\title{
CRÔNICAS NA FORMAÇÃO DOCENTE: EM BUSCA DA ALEGRIA NA ESCOLA
}

\author{
CRÓNICAS EN LA FORMACIÓN DOCENTE: EN LA BÚSQUEDA DE LA ALEGRÍA \\ EN LA ESCUELA
}

CHRONICLES IN TEACHER EDUCATION: IN SEARCH OF JOY IN SCHOOL

Ivan FORTUNATO ${ }^{1}$

RESUMO: Este artigo é um relato de experiência produzido a partir do resultado final da disciplina "Escola e Currículo" do curso de formação docente, realizada no segundo semestre de 2019. O trabalho pedagógico foi conduzido por meio de crônicas, as quais foram reunidas em um livro digital de distribuição gratuita. Ao final, um balanço desse trabalho foi realizado coletivamente, tendo sido reconhecido que a reflexão do cotidiano escolar por meio das crônicas, além do desafio coletivo de se produzir um livro se tornaram elementos fundamentais para a proposta inicial de se pensar (e viver) a alegria na escola.

PALAVRAS-CHAVE: Crônicas. Formação docente. Relato de experiência.

RESUMEN: Este articulo es un informe de experiencia producido a partir del resultado final de la disciplina "Escuela y Currículum" del curso de capacitación docente, realizado en el segundo semestre de 2019. El trabajo pedagógico se realizó a través de crónicas, que se recopilaron en un libro digital de distribución gratuita. Al final, se realizó un balance de este trabajo colectivamente, habiéndose reconocido que el reflejo de la vida diaria de la escuela a través de las crónicas, además del desafio colectivo de se produzir um libro, se convirtió en elementos fundamentales para la propuesta inicial de pensar (y vivir) la alegría en la escuela.

PALABRAS CLAVE: Crónicas Formación del profesorado. Informe de experiencia.

ABSTRACT: This paper is an experience report produced from the final result of the discipline "School and Curriculum" of the teacher formation course, held in the second semester of 2019. The pedagogical work was conducted through chronicles, which were gathered in a digital book of free distribution. At the end, a balance of this work was carried out collectively, having been recognized that the reflection of the school daily life through the chronicles, in addition to the collective challenge of producing a book, became fundamental elements for the initial proposal to think (and live) the joy at school.

KEYWORDS: Chronicles. Teacher formation. Experience report.

${ }^{1}$ Instituto Federal de Educação, Ciência e Tecnologia de São Paulo (IFSP), Itapetininga - SP - Brasil. Docente na Coordenadoria de Formação Pedagógica. Brasil. Professor do Programa de Pós-Graduação em Educação (UFSCar). Doutorado em Desenvolvimento Humano e Tecnologias (UNESP) e em Geografia (UNESP). ORCID: https://orcid.org/0000-0002-1870-7528. E-mail: ivanfrt@yahoo.com.br 
Antes de ler o livro que o guru lhe deu, você tem que escrever o seu. (Raul Seixas, Todo Mundo Explica, 1978)

Este artigo é um relato de experiência produzido a partir do resultado final da disciplina "Escola e Currículo" do curso de formação docente, realizada no segundo semestre de 2019, no Instituto Federal de São Paulo, campus de Itapetininga, no sudoeste paulista. Adendo necessário: o curso de formação docente é o Programa Especial de Formação de Professores para a Educação Básica, ancorado pela Resolução CNE no. 2 de 26 de junho de 1997, cujo artigo 10 resolve que "o concluinte do programa especial receberá certificado e registro profissional equivalentes à licenciatura plena". O curso tem sido ofertado pelo campus de Itapetininga desde 2011, tendo mantido oferta regular desde o ano de 2017, tem recebido estudantes egressos de várias áreas, como direito, enfermagem, administração, engenharia, gestão ambiental, análise e desenvolvimento de sistemas etc. Esses estudantes têm como objetivo comum a docência, seja como a busca por uma nova carreira, seja como formação continuada para aqueles que já estão em atividade no magistério.

Dentre o rol de disciplinas do curso, temos esta nomeada como "Escola e Currículo", cuja ementa expressa como objetivo central a "compreensão de currículo de maneira integrada e contextual compreendendo-o como campo de análise crítica e sociológica ${ }^{2}$. Eis, então, que ao retomar as leituras obrigatórias para planejar a condução da disciplina encontrei, em Sacristán Gimeno (1998, p. 121), a expressão de algo bastante óbvio, contudo preocupante para o contexto da formação docente: "os conteúdos, por vias diversas, são moldados, decididos, selecionados e ordenados fora da instituição escolar, das aulas, das escolas e à margem dos professores/as". Tal preocupação foi ao encontro de uma busca recente a respeito do próprio sentido da escola, como local de preparação para o futuro em detrimento do momento vivido, negando a alegria da vida à sua própria comunidade - estudantes e professores (FORTUNATO, 2020; SNYDERS, 2001).

A alegria é - ou ao menos deveria ser - elemento fundante da vida cotidiana, incluindo, certamente, o tempo de escola. Rubem Alves (1994, p. 11) havia percebido isso, anotando o quanto é importante entender que na escola se deve(ria) ensinar coisas cheias de alegria; embora o próprio tenha ouvido de colegas professores que não há tempo para isso, pois primeiro devese ensinar matemática, literatura, português ou ciências. "Estou com medo de que [...] me chamem de mentiroso", afirmou o autor, "pois eu disse que o negócio dos professores é ensinar

${ }^{2} \mathrm{O}$ ementário faz parte do Projeto Pedagógico do Curso. Disponível em: https://itp.ifsp.edu.br/index.php/ensinosuperior/2-uncategorised/103-formacao-pedagogica. Acesso em: dez. 2019. 
felicidade". De fato, o próprio Rubem Alves (1994, p. 12) anotou que as experiências de felicidade e alegria da escola são aquelas que acontecem apesar da escola, mencionando, dentre outras, as amizades, o companheirismo, as traquinagens, as aulas vagas, os passeios... "mas pouquíssimas serão as referências à alegria de estudar, compreender e aprender".

Assim, as constatações de que temos um currículo que é construído de fora para dentro e as de que a escola é um local inerte, sem tempo para a alegria, o planejamento da disciplina "Escola e Currículo" foi colocado em apenso, pois era preciso tratar desses elementos com os estudantes do curso de formação docente. O que pensavam sobre essa proposta de currículo vinda de fora, cada vez mais comum a todos estudantes sob o nome de Base Nacional Comum Curricular? E teria sido seu tempo de escolarização vivido sem alegria, sendo suas memórias mais agráveis aquelas mencionadas por Rubem Alves (1994), isto é, as que parecem nada dizer a respeito do processo de aprender? E para aqueles que são professores, há momentos possíveis de se ensinar alegria, ou o currículo que vem de fora toma todo seu tempo, inclusive extraclasse?

Com essas questões, então, iniciamos nosso semestre letivo. Para tornar ainda mais severo o exame crítico de toda conjuntura que essas indagações contemplam, foi lida a crônica "Sobre vacas e moedores" de Rubem Alves (1994). Nela, o autor compara a escola a um açougue, sendo que há um processo de transformar seres oníricos, ontológicos e singulares em algo uniforme, seriado e útil, de alguma forma, para a sociedade industrial de consumo. A escrita é sombria, pois revela um sentimento de angústia com relação à escola que, tal qual um moedor de carne, tritura os sonhos dos jovens estudantes, que vão se tornando uma classe homogênea de profissionais úteis (e necessários) à sociedade, mas, lamenta Alves (1994, p. 35), “que pena - não sabem sonhar...”. Não obstante, ao escrever sobre a alegria de ensinar faz um apelo a nós, professores e professoras: que ajudemos o alunado a ser feliz. Tarefa difícil.

Dessa feita, logo depois de lançar os questionamentos sobre "escola" e "currículo" junto com a metáfora melancólica de Rubem Alves (1994), passei a ouvir as opiniões dos estudantes, colhendo suas impressões a respeito dessas angústias partilhadas. Tudo isso estaria fazendo sentido?

Aos poucos, alguns relatos foram sendo também partilhados, praticamente assentindo com o que foi colocado: a escola parecia, mesmo, negacear essa ideia de alegria e felicidade, deixando isso para os momentos em que não havia "escola", ou seja, o recreio, o momento que antecede o sinal de entrada para sala de aula, e as horas do dia que restam depois do sonoro sinal que dispensa seus estudantes (com tarefa, pois, primeiro a obrigação). Esses relatos também assentiam com a ideia de que a escola poderia (e deveria) ser um lugar de felicidade, afinal, quem ensina sem alegria também tem seus sonhos macerados, restando-se, apenas, útil. 
Veio, então, a proposta de se (re)pensar os dois eixos centrais da disciplina, escola e currículo, por meio de crônicas. "Mas, professor, o que é uma crônica?" - prontamente fui questionado. "E se a gente fizesse um estudo sobre crônicas" - propôs um estudante. "Poderíamos ler várias crônicas e até convidar uma professora de literatura para nos explicar como fazer" - sugeriu outro, consentido com o anterior. E logo já estávamos propensos a repetir a fórmula da escola: alguém nos diz o que e como fazer, para, então, sermos avaliados por quem nos disse o que e como fazer, a partir de seu próprio ponto de vista. E isso é vicioso, claro.

Disse não saber o que são nem como se estruturam crônicas. Antecipando às críticas axiomáticas de que não deveria me atrever a propor algo desconhecido, li a crônica de Rubem Alves (1994) intitulada "ensinar o que não se sabe". Além disso, prontamente expliquei o "método livre" de Célestin Freinet o qual, explicado de forma bastante simples, inverte o trabalho da escola: primeiro se faz, depois se estuda sistematicamente o que foi feito - vale a pena conferir essa fórmula, trabalhada com mais propriedade em outro manuscrito (FORTUNATO, 2018). “O que acham, então, de nos arriscarmos a produzir crônicas, mesmo sem nunca ter escrito, ou mesmo lido, uma?" - propus novamente ao alunado. Desafio aceito. Estávamos no primeiro dia letivo do semestre.

Dessa forma, as semanas seguintes foram dedicadas ao planejamento das atividades, buscando responder perguntas pragmáticas do tipo "até quando devemos produzir nossas crônicas?", ou "haverá momentos de leitura da produção?", ou, ainda, "como saber se escrevemos algo que o professor quer?". Ao longo de duas aulas (havia uma aula por semana), fomos coletivamente dialogando a respeito dessas - e outras - dúvidas, tentando formular algum tipo de organização para a disciplina "Escola e Currículo"; afinal, a disciplina não flutuava no ar, isto é, fazia parte de um complexo sistema institucional, com prazos, critérios de avaliação para aprovação ou reprovação, controle de presença etc.

Passadas três semanas do início das aulas, tínhamos um cronograma relativamente bem ajeitado, reservando dias para produção da escrita em sala e momentos de paragem para leitura, com o propósito de tornar coletivo o trabalho individual, pois os colegas poderiam comentar tanto sobre o conteúdo quanto sobre a forma da crônica em desenvolvimento. $\mathrm{O}$ calendário previa, ainda, a data final para entrega da escrita, incluindo aulas suficientes para que houvesse devolutivas. Assim, o trabalho pedagógico da disciplina foi conduzido por meio da escrita individual de crônicas.

Inicialmente, tentamos respeitar nosso próprio cronograma. Mas, fomos lidando com situações diversas, as quais demandavam um constante retorno ao calendário, de forma que fosse possível concluir o proposto dentro do período letivo. Havia a insegurança de alguns, que 
não tinham certeza de que estavam produzindo "crônicas", buscando constante aprovação. Outros, ansiosos demais, desejavam concluir em poucas horas de trabalho suas crônicas, sendo necessários desafiá-los e desafiá-las a continuar refinando seu escrito. Enfrentamos, ainda, a dificuldade de começar a escrita, o que foi sentido por vários estudantes.

Com isso, ao longo do nosso trabalho na disciplina, fomos incluindo momentos diversificados no cronograma, como forma de estimular a criatividade para a escrita. Trabalhamos bastante com lembranças do tempo escolar, buscando avivar memórias sobre alegria e felicidade vividas na (e por causa da) escola. Houve um dia, por exemplo, em que jogamos futebol; não foi planejado nem nada, mas o dia estava agradável, havia um gramado, duas traves e uma bola disponível. Aproveitamos para relembrar as aulas de Educação Física e as práticas esportivas na escola, discutimos gênero também, pois o esporte tem essa coisa de menino e de menina. Outra atividade incluída no calendário, como forma de potencializar a escrita, foi a acolhida, em nossa disciplina, de jovens estudantes dos anos finais do ensino fundamental de uma escola estadual circunvizinha, para discutirmos sobre "projetos de vida" oportunidade importantíssima para conhecermos mais sobre a escola e sobre esses seres de sonhos, mencionados nas crônicas de Rubem Alves (1994). Em outra oportunidade, inclusive, os jovens devolveram a hospitalidade, nos recebendo em sua escola, em sua sala de aula, partilhando seu cotidiano estudantil.

Essas atividades, combinadas com os momentos de paragem, foram o bastante para que o desafio de produzir crônicas sobre escola e/ou sobre currículo fosse alcançado por todos os estudantes do curso de formação docente. Ao longo do processo, conforme iam concluindo suas escritas, elas eram lidas para a classe com o propósito de refinamento, a partir da devolutiva coletiva. Conforme concluíam as crônicas, passavam a ajudar os demais a ter ideias, por meio de exercícios de escuta ativa. Ao final do processo, o trabalho foi considerado exitoso por todos, tendo se reunido as crônicas produzidas em um livro impresso e digital, de distribuição gratuita (FORTUNATO, 2019). O lançamento desse livro foi feito, na penúltima semana de aula do semestre, no salão nobre da escola mais antiga da cidade, curiosamente a primeira escola normal do interior paulista, a Escola Estadual Peixoto Gomide ${ }^{3}$. Na ocasião, cada estudante presente pode subir ao palco e ler sua produção, revelando a emoção que havia em cada frase escrita.

Essas crônicas contêm as mais variadas histórias da escola. Alguns usaram suas lembranças como estudantes, outros como docentes. Há também histórias que foram nascendo das atividades desenvolvidas ao longo do semestre, seja da própria disciplina, seja de outras

${ }^{3}$ Foi escrito um artigo sobre escola. Ver Fortunato (2017). 
disciplinas ou mesmo do estágio supervisionado desenvolvido em escolas públicas. Existem poemas, metáforas, fantasias... assim como histórias vividas de superação e enfrentamento na e pela educação. Trata-se de um livro pensado, desenvolvido e apresentado dentro de uma disciplina do curso de formação docente, como elemento central de todo processo de ensino e aprendizagem. Foi sobre isso que discutimos na nossa última semana de aula, reservada justamente para uma avaliação coletiva do trabalho.

Ao final, depois de concluído o balanço da disciplina "Escola e Currículo", ficou patente que a reflexão do cotidiano escolar realizada por meio das crônicas, além do desafio coletivo proposto de se realizar um trabalho escrito, a respeito de algo que não se sabia ao certo como fazer, se tornaram elementos fundamentais para a proposta inicial de se pensar (e viver) a alegria na escola. De certa forma, ficou registrada na coletânea a satisfação de escrevê-la e, certamente, permanecerá viva na memória de todos que participamos desse processo, como um exemplo de como se pode aprender e ensinar alegria, indo em direção diferente do que se apresenta o currículo que vem de fora.

\section{REFERENCIAS}

ALVES, R. A alegria de ensinar. São Paulo: ARS Poética Editora, 1994.

FORTUNATO, I. (org.) Crônicas da escola: fragmentos do cotidiano. Itapetininga: Edições Hipótese, 2019. Available: https://hipotesebooks.wixsite.com/cazulo/catalogo. Access: dec. 2019.

FORTUNATO, I. A epistemologia da formação docente: o que se pode aprender com o empirismo de Freinet. Revista ibero-americana de estudos em educação, Araraquara, v. 13, n. esp., p. 1995-2007, 2018.

FORTUNATO, I. Educação e o tempo presente: menos carpe diem, mais alegria na escola. Quaestio (UNISO), 2020. [no prelo]

FORTUNATO, I. Por que a Escola Normal de Itapetininga foi batizada de Peixoto Gomide? Nucleus, Ituverava, v. 14, n. 1, p. 67-78, 2017.

SACRISTÁN GIMENO, J. O currículo: os conteúdos do ensino ou uma análise prática. In: SACRISTÁN GIMENO, J.; PÉREZ GÓMEZ, A. I. Compreender e transformar o ensino. 4. ed. Porto Alegre: ArtMed, 1998. p. 119-148.

SNYDERS, G. Alunos felizes: reflexão sobre a alegria na escola a partir de textos literários. 3. ed. São Paulo: Paz e Terra, 2001. 
Como referenciar este artigo

FORTUNATO, I. Crônicas na formação docente: em busca da alegria na escola. Rev. Sem Aspas, Araraquara, v. 9, n. 1, p. 97-103, jan./jun., 2020. e-ISSN: 2358-4238. DOI: https://doi.org/10.29373/sas.v9i1.14119

Submetido em: 10/06/2020

Revisões requeridas: $20 / 08 / 2020$

Aprovado em: 05/09/2020

Publicado em: 30/09/2020 